\title{
Meis1 is an essential and rate-limiting regulator of $M L L$ leukemia stem cell potential
}

\author{
Piu Wong, ${ }^{1}$ Masayuki Iwasaki, ${ }^{1}$ Tim C.P. Somervaille, ${ }^{1}$ Chai Wai Eric So ${ }^{2}$ and Michael L. Cleary ${ }^{1,3}$ \\ ${ }^{1}$ Department of Pathology, Stanford University School of Medicine, Stanford, California 94305, USA; ${ }^{2}$ Haemato-Oncology \\ Section, The Institute of Cancer Research, Sutton, Greater London SM2 5NG, United Kingdom
}

\begin{abstract}
Oncogenic mutations of the MLL histone methyltransferase confer an unusual ability to transform non-self-renewing myeloid progenitors into leukemia stem cells (LSCs) by mechanisms that remain poorly defined. Misregulation of Hox genes is likely to be critical for LSC induction and maintenance but alone it does not recapitulate the phenotype and biology of $M L L$ leukemias, which are clinically heterogeneouspresumably reflecting differences in LSC biology and/or frequency. TALE (three-amino-acid loop extension) class homeodomain proteins of the $\mathrm{Pbx}$ and Meis families are also misexpressed in this context, and we thus employed knockout, knockdown, and dominant-negative genetic techniques to investigate the requirements and contributions of these factors in MLL oncoprotein-induced acute myeloid leukemia. Our studies show that induction and maintenance of $M L L$ transformation requires Meis1 and is codependent on the redundant contributions of $P b x 2$ and $P b x 3$. Meis1 in particular serves a major role in establishing LSC potential, and determines LSC frequency by quantitatively regulating the extent of self-renewal, differentiation arrest, and cycling, as well as the rate of in vivo LSC generation from myeloid progenitors. Thus, TALE proteins are critical downstream effectors within an essential homeoprotein network that serves a rate-limiting regulatory role in $M L L$ leukemogenesis.
\end{abstract}

[Keywords: Leukemia stem cells; MLL; Meis1; Pbx; TALE homeodomain proteins]

Supplemental material is available at http://www.genesdev.org.

Received August 7, 2007; revised version accepted September 12, 2007.

Leukemia stem cells (LSCs) comprise a functionally distinct subpopulation of leukemic cells with the ability to self-renew extensively, and to initiate, sustain, or regenerate disease. In acute myeloid leukemia (AML), LSCs are generally considered to be rare upstream cells that arise out of the normal hematopoietic stem cell (HSC) or primitive progenitor compartments, and are organized in a hierarchy based on quantitative differences in their self-renewal potentials (Passegue and Weisman 2005). This paradigm, however, may not apply to all myeloid leukemias, as suggested by recent studies using a mouse model of AML induced by the MLL-AF9 oncogene (Krivtsov et al. 2006; Somervaille and Cleary 2006), which is typically associated with FAB-M4 or M5 subtypes of human AML (Swansbury 1998). LSCs were found to be very frequent and representative of downstream myeloid lineage cells that ectopically acquired extensive self-renewal and other biologic properties more typical of HSCs. The key regulators and subordi-

${ }^{3}$ Corresponding author.

E-MAIL mcleary@stanford.edu; FAX (650) 498-6222.

Article published online ahead of print. Article and publication date are online at http://www.genesdev.org/cgi/doi/10.1101/gad.1602107. nate genetic programs by which MLL converts myeloid progenitors into LSCs are of major interest.

MLL is a histone methyltransferase with features suggestive of a general transcriptional role at most promoters (Guenther et al. 2005); however, Hox genes appear to be particularly dependent on its function (Yu et al. 1995). In leukemias harboring MLL-activating mutations, several Hoxa genes are consistently expressed at high levels, suggesting that MLL oncoproteins inappropriately maintain their expression and prevent their programmed down-regulation that otherwise accompanies terminal myeloid differentiation (Imamura et al. 2002b; Pineault et al. 2002). Since various Hox genes have been implicated in the regulation of normal stem cell self-renewal, their misregulation in $M L L$ leukemias is likely to be important for LSC maintenance. Hoxa9, in particular, has been shown to critically influence $M L L$ oncogenesis (Ayton and Cleary 2003; Kumar et al. 2004; So et al. 2004; Okada et al. 2005; J. Wang et al. 2005). However, Hox gene misregulation alone does not recapitulate the biological and clinical features of $M L L$ leukemia.

Additional candidate factors that may critically regulate LSC potentials in MLL leukemias are TALE (threeamino-acid loop extension) class homeodomain proteins 
of the Pbx and Meis families. They enhance the relatively nonspecific DNA-binding properties of Hox transcription factors and regulate gene expression as heterooligomeric complexes with Hox proteins (Mann 1995). TALE proteins are required for the execution of some Hox-dependent developmental programs and are implicated in leukemogenesis (Azpiazu and Morata 1998; Ryoo et al. 1999; Selleri et al. 2001; Manley et al. 2004; Eklund 2007; Rice and Licht 2007). Notably, mutations of Hoxa9 that prevent interactions with $\mathrm{Pbx}$ proteins abrogate its oncogenic properties (Schnabel et al. 2000). Furthermore, coexpression of Meis1 markedly shortens the latency and increases the penetrance of Hoxa9-induced myeloid leukemia, and recapitulates some of the features of $M L L$ leukemia (Kroon et al. 1998; Calvo et al. 2001; Zeisig et al. 2004; G.G. Wang et al. 2005). Since Meis1 is also a transcriptional target of MLL oncoproteins and is consistently highly expressed in $M L L$ leukemias (Lawrence et al. 1999; Imamura et al. 2002b; Milne et al. 2005), simultaneous misregulation of Hoxa9 and Meis1 may be sufficient for $M L L$ oncogenesis (Zeisig et al. 2004). However, $M L L$ leukemias are biologically and clinically diverse, and the specific roles of TALE proteins in regulating LSC properties that underlie these differences have not been defined.

In this report, we demonstrate that TALE homeodomain proteins are essential for the induction and maintenance of MLL leukemogenesis. Meis1, in particular, quantitatively regulates the differentiation arrest, cycling activity, in vivo progression, and self-renewal of $M L L$ leukemia cells, thereby functioning as a critical and rate-limiting determinant of LSC potential.

\section{Results}

The latencies of MLL leukemias correlate with Meis1 endogenous expression levels

Twelve different MLL fusion oncoproteins were investigated for their TALE protein-dependent oncogenic properties. These included MLL oncoproteins containing different classes of fusion partners including cytoplasmic proteins (GAS7, AF1P, AF6, and EB1), nuclear proteins of the forkhead family (FKHRL1 and AFX) or AF4 family/ complex (LAF4, AF5, ENL, AF9, and AF10), and histone modifiers (CBP), which induce leukemia with widely varying latencies and morphologies in mice (Lavau et al. 1997, 2000; DiMartino et al. 2002; So et al. 2003, 2004; J. Wang et al. 2005; Somervaille and Cleary 2006; our unpublished observations). E2A-HLF served as a control, since it transforms myeloid progenitors through Hoxindependent pathways (Ayton and Cleary 2003; So et al. 2004). Retroviral constructs for each of the respective $M L L$ fusion cDNAs expressed proteins that migrated at their predicted molecular weights in Western blot analysis (Supplementary Fig. 1A).

Primary murine myeloid progenitors $\left(\mathrm{c}-\mathrm{kit}^{+}\right)$transduced by the $12 M L L$ fusion constructs, but not empty vector, formed colonies in methylcellulose that replated through at least four rounds of culture (data not shown), demonstrating the enhanced self-renewal and impaired differentiation typically induced by $M L L$ oncogenes (Lavau et al. 1997, 2000). Real-time quantitative PCR analysis of cells from fourth-round cultures showed that Hoxa5, Hoxa7, Hoxa9, and Hoxa10 were highly expressed in myeloid cells transduced by $M L L$ oncogenes compared with control (E2A-HLF) cells under our experimental conditions (Supplementary Fig. 1B,C). The relative and absolute levels of these Hox transcripts were fairly uniform, and did not appear to distinguish the different molecular subtypes of $M L L$-transformed cells.

Conversely, absolute Meis1 expression levels varied considerably among the different $M L L$-transformed cells, from twofold to 40-fold the levels detected in control (E2A-HLF) cells (Fig. 1A). Meis2 and Meis3 were also expressed, but not consistently increased relative to their levels in cells transformed by E2A-HLF, such that Meis1 accounted for $75 \%-95 \%$ of total Meis transcripts in $M L L$-transformed cells (Fig. 1B). Interestingly, Meis1 transcript levels showed a significant correlation with the latencies for MLL leukemia (Fig. 1C; Supplementary Table 1). Cells transformed by MLL fusion proteins that induce a short latency AML in murine models displayed higher levels of Meis1 expression, whereas those that induce AML with prolonged latencies displayed lower levels of Meis1 expression. Statistical analysis showed a power relationship, indicating that Meis1 transcript levels decreased at a specific rate with respect to increasing time required for leukemia development. Conversely, Hoxa9 expression levels showed no correlation with leukemia latencies (Supplementary Fig. 2). These results suggested that Meis1 likely serves a critical and potentially rate-limiting role in the pathogenesis of $M L L$ leukemia.

Meis1 is essential for induction and maintenance of MLL-mediated transformation

To specifically address the requirement for Meis1 in MLL-mediated oncogenesis, transformation assays were performed using fetal liver (FL) cells isolated from Meis $1^{-/-}$embryos at embryonic day 13.5 (E13.5), prior to their intrauterine demise at approximately E14 (Hisa et al. 2004). Meis1-deficient FL cells were efficiently transformed by the control E2A-HLF gene; however, none of the $M L L$ oncogenes was capable of inducing sustained replating (Fig. 2A). Rather, the plating capacities of $M L L$ transduced cells were exhausted after the second round. Meis $1^{-/-}$second-round colonies were small in size with a diffuse morphology and contained markedly reduced numbers of myeloid blasts when compared with transformed colonies from wild-type FL (Fig. 2B). Conversely, all tested $M L L$ oncogenes induced continued replating of E13.5 FL cells isolated from wild-type mice. Moreover, transformation of Meis $1^{-1-}$ FL cells by MLL-AF9 was rescued by cotransduction of Meis1 (Fig. 2A), demonstrating that the progenitors susceptible to $M L L$ transformation were present in Meis $1^{-/-}$FLs at E13.5. Thus, in the absence of Meis1, MLL oncogenes are incapable of inducing 
Wong et al.

A

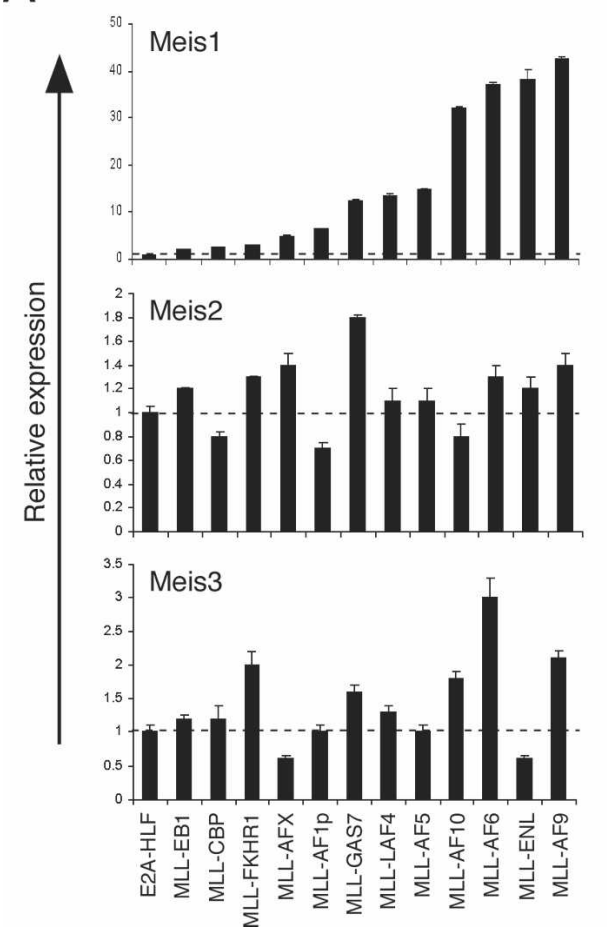

B

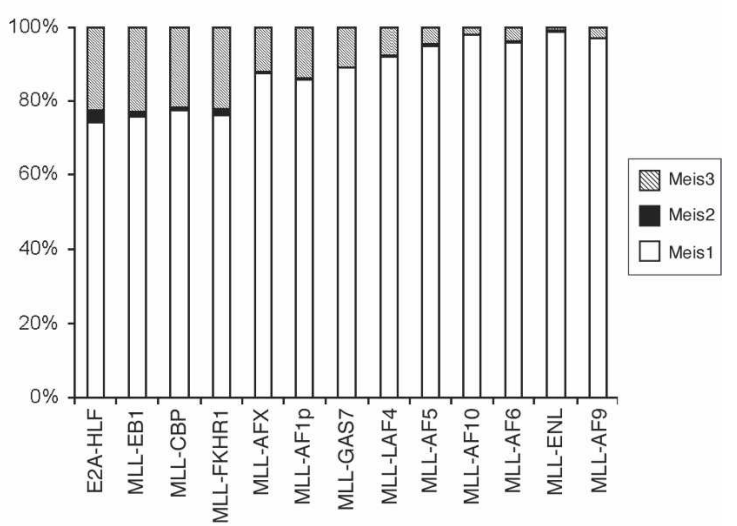

C

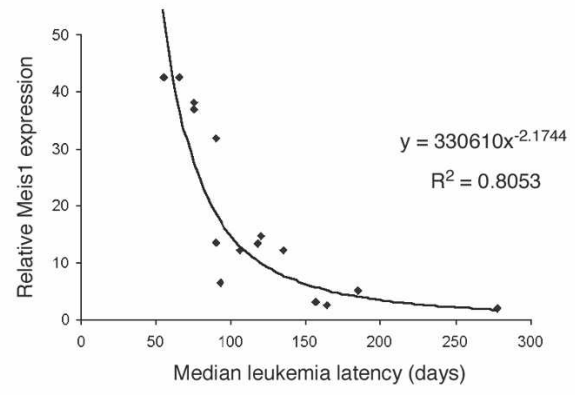

Figure 1. Meis1 expression levels correlate with the latencies of $M L L$ leukemias. (A) The expression levels of Meis1, Meis2, and Meis3 transcripts were determined by real-time PCR analysis of $M L L$-transformed cells (indicated below) from the fourth round of serial replating (error bars indicate standard deviations of triplicate analyses). Results are expressed relative to levels observed in cells transformed by E2A-HLF (dashed line). (B) Bar graph indicates the total relative levels of Meis transcripts expressed in cells transformed by various oncogenes (indicated at bottom) from the fourth round of plating in methylcellulose cultures. The relative abundance of Meis transcripts was determined using the cycle time $(\mathrm{Ct})$ value method, assuming that all primers were optimized to generate equal PCR efficiencies. $(C)$ The relative expression levels of Meis1 are plotted against median latency times required for leukemia induction by the respective $M L L$ oncogenes. Latency data are derived in part from the current study as well as published studies (Supplementary Table 1). The data display a power trend line best-fit $\left(\mathrm{R}^{2}=0.8053\right)$ indicating that Meis1 expression levels decrease at a specific rate with respect to the time required for leukemia development.

the enhanced self-renewal and impaired differentiation necessary for myeloid transformation.

To assess whether Meis1 was required for maintenance of $M L L$-mediated transformation, wild-type cells stably transformed by $M L L$ oncogenes were secondarily transduced with lentiviral vectors expressing short hairpin RNAs (shRNAs) to specifically silence Meis1 (Supplementary Fig. 3). Expression of two different Meis1 shRNAs resulted in substantial impairment $(>70 \%-80 \%)$ of clonogenic capacity compared with $M L L$-transformed cells secondarily transduced with lentiviral vector alone (Fig. 2C). Similarly, MLL-transformed cells displayed a marked reduction in clonogenic capacity $(>80 \%)$ when secondarily transduced with a dominantnegative construct that lacked the Meis1 DNA-binding homeodomain, whereas E2A-HLF-transformed cells were unaffected (Fig. 2D). Therefore, Meis1 is essential for both the initiation and maintenance of enhanced selfrenewal imposed on myeloid progenitors by $M L L$ oncogenes.

MEIS1 has been reported to be consistently expressed in human $M L L$ leukemias (Imamura et al. 2002b; Ferrando et al. 2003; Quentmeier et al. 2004), suggesting that it may serve a similar role in their maintenance. Quantitative RT-PCR analysis showed that MEIS1 was expressed in leukemia cell lines with $M L L$ chromosomal translocations (Fig. 2E). However, in contrast with murine $M L L$-transformed cells, MEIS2 was also substantially expressed and ML2 cells were notable for expressing 10-fold more MEIS2 versus MEIS1 (Fig. 2E). Lentiviral transduction of two different MEIS1 shRNAs resulted in substantial impairment $(-40 \%-60 \%)$ of clonogenic capacity for $M L L$ leukemia cell lines compared with control K562 cells with the exception of ML2 cells, which were not significantly compromised (Fig. 2F). Thus, despite the redundancy of MEIS gene expression, our results suggest that it is nevertheless required to maintain human $M L L$ leukemias.

\section{Hyperexpression of Meis1 accelerates the progression of MLL leukemogenesis}

The observed correlation of endogenous Meis1 expression levels with leukemia latency and the requirement of Meis1 for $M L L$-mediated stem and progenitor cell transformation raised the possibility that Meis1 may di- 
A

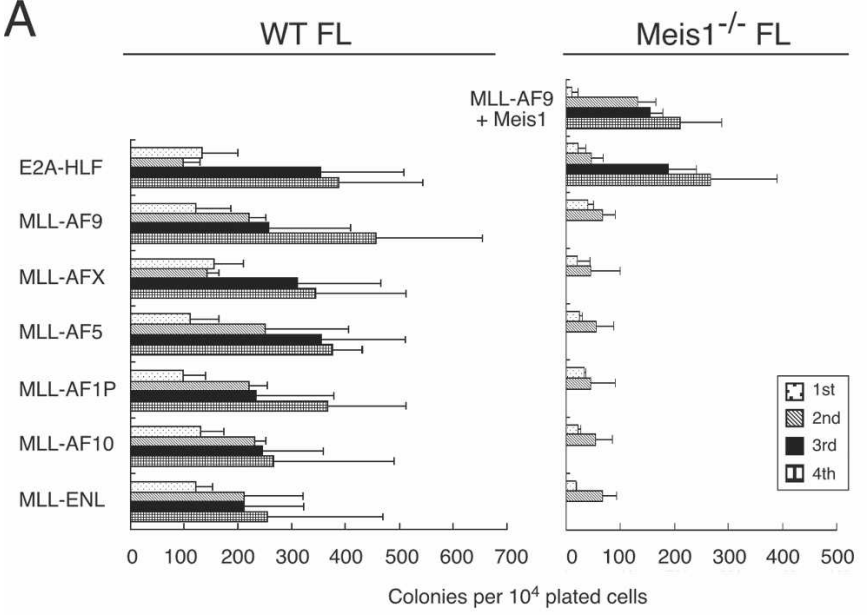

C

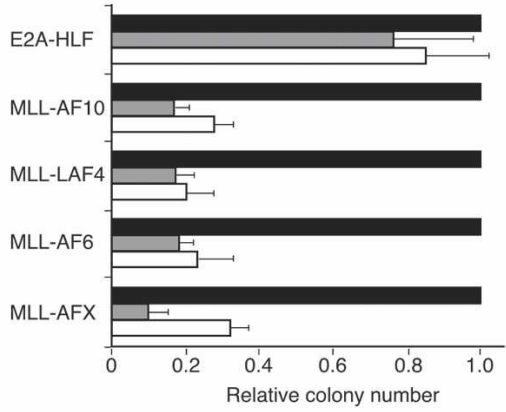

E

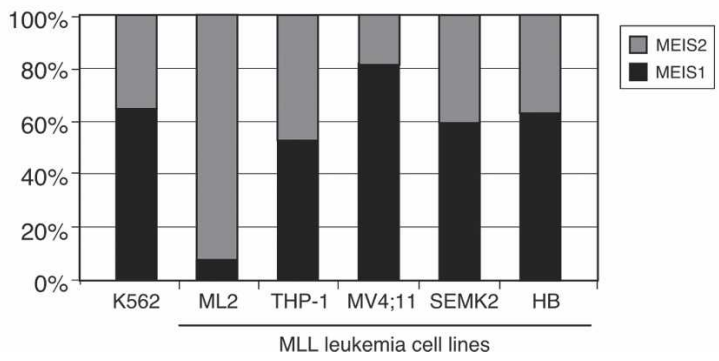

B
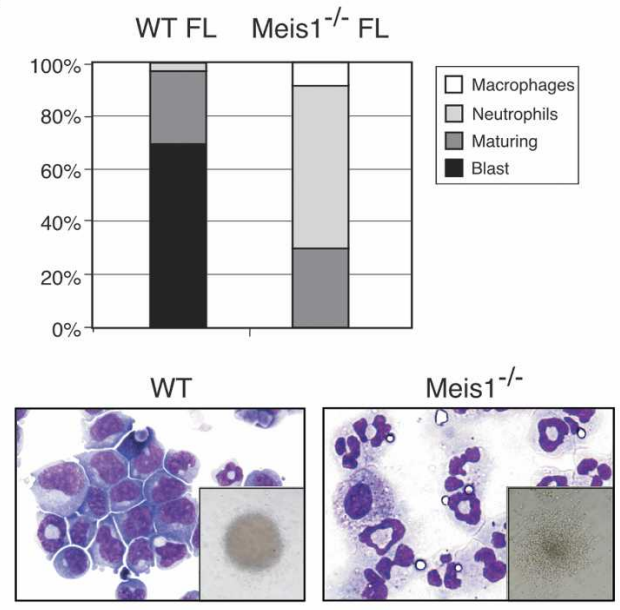

D

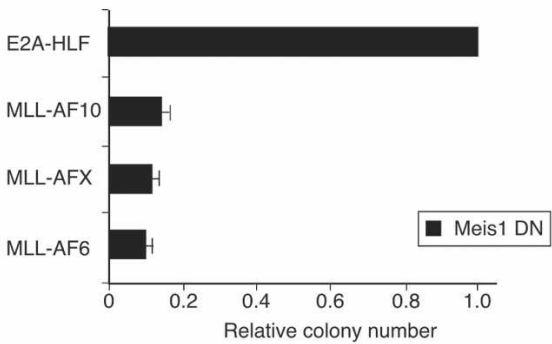

F

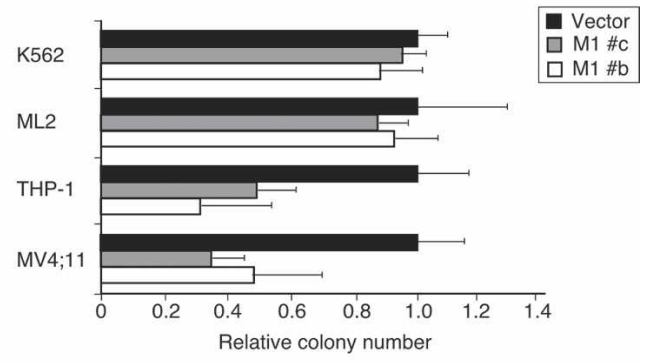

Figure 2. Meis1 is required for initiation and maintenance of $M L L$-mediated myeloid transformation. (A) FL cells from wild-type (left) or Meis $1^{-/-}($right $)$mice were transduced with fusion oncogenes (indicated on left) and serially plated in methylcellulose cultures every $5 \mathrm{~d}$. Results are shown as colony numbers per $10^{4}$ plated cells for each round of culture. Data are also shown for Meis $1^{-/-}$cells cotransduced with MLL-AF9 and Meis1. Error bars indicate standard deviations of three independent experiments. (B) Cytospin preparations of wild-type (left) or Meis ${ }^{-/-}$(right) FL cells transduced with MLL-AF9 were analyzed for the proportions of cells at the end of the second round of plating in methylcellulose culture with morphological features of blasts versus differentiation (May Grunwald Giemsa staining). Bar graph indicates the mean number of cells with the indicated morphologic features $(n=4)$. Insets show colony morphologies at the end of the second round. (C) Myeloid progenitors transformed by various $M L L$ oncogenes (indicated on left) were secondarily transduced with lentiviral vectors encoding shRNAs specific for Meis1 (M1 \#1 or M1 \#2). Colony numbers are shown relative to cells secondarily transduced with lentiviral vector alone. Error bars indicate standard deviations of at least two independent experiments. $(D)$ Myeloid progenitors transformed by various oncogenes (indicated on left) were secondarily transduced with a dominant-negative Meis1 construct (Meis1 DN). Colony numbers are shown relative to cells transformed by E2A-HLF. Error bars indicate standard deviations of at least two independent experiments. $(E)$ Bar graph indicates the total relative levels of MEIS1 and MEIS2 transcripts expressed in human leukemia cell lines (indicated at bottom). The relative abundance of MEIS transcripts was determined using the Ct value method, assuming that all primers were optimized to generate equal PCR efficiencies. $(F)$ Human leukemia cell lines (indicated on left) were transduced with lentiviral vectors encoding shRNAs specific for MEIS1 (M1 \#b or M1 \#c). Colony numbers are shown relative to cells transduced with lentiviral vector alone. Error bars indicate standard deviations of at least two independent experiments.

rectly influence the in vivo generation of LSCs from myeloid progenitors, which requires undefined secondary alterations (Lavau et al. 2000; Somervaille and Cleary
2006). To investigate this possibility, Meis1 was hyperexpressed along with representative $M L L$ oncogenes (MLL-AF10, MLL-GAS7, or MLL-LAF4) to determine 
whether its enhanced expression may accelerate $M L L$ leukemogenesis. Myeloid progenitors $\left(\mathrm{c}-\mathrm{kit}^{+}\right)$cotransduced with an $M L L$ oncogene plus Meis1 (MLL/Meis1) displayed Meis1 transcript levels that were several-fold higher than progenitors cotransduced with the respective $M L L$ oncogene plus empty vector $(M L L / V)$ prior to transplantation (Fig. 3A). Following transplantation of equal numbers of cotransduced cells (representing comparable numbers of colony-forming cells [CFCs]) into syngeneic recipient mice, the $M L L / M e i s 1$ cohorts developed leukemia with substantially shortened latencies compared with mice transplanted with $M L L / v$ cotransduced cells (Fig. 3B). Leukemias in both cohorts appeared grossly similar pathologically-with effacement of the normal bone marrow architecture, marked splenomegaly, and infiltration of the liver by leukemia cellsand maintained similar levels of Meis 1 when compared with the respective primary cotransduced progenitors (data not shown). Therefore, Meis1 serves a rate-limiting role in progression of $M L L$-associated leukemia.

Meis1 modulates the differentiation arrest, self-renewal, and cell cycle activity of MLL leukemia cells

FACS analysis demonstrated that all leukemias were donor-derived (data not shown) and consistently displayed myeloid phenotypes $\left(\mathrm{Mac}^{+} \mathrm{Gr}^{+}\right)$. However, a greater fraction of $M L L / M e i s 1$ leukemia cells expressed highlevel c-kit and lower Mac1, suggestive of less differentiation (Fig. 4A). Morphologic assessment of splenocytes obtained at necropsy of $M L L /$ Meis 1 mice revealed a several-fold higher proportion of cells with cytologic fea- tures of blasts and substantially fewer differentiating forms (Fig. 4B) compared with splenocytes from $M L L / V$ mice. Furthermore, in semisolid culture assays, the frequencies of CFCs in the spleens of leukemic mice were up to sevenfold higher for $M L L / M e i s 1$ leukemias (Fig. 4C) and colony morphologies (Lavau et al. 1997) were predominantly type I for $M L L /$ Meis1 CFCs, compared with mostly type II/III for $M L L / V$ CFC $(72 \%$ vs. $21 \%$ for MLL-AF10 leukemias) (data not shown). Thus, $M L L$ leukemias where Meis1 was overexpressed exhibited a more pronounced block in differentiation as well as a higher frequency of clonogenic leukemia cells.

Cell cycle analysis of explanted leukemia cells growing in methylcellulose cultures revealed a significant increase in the proportion of S/G2/M-phase cells for $M L L /$ Meis1 versus $M L L / V$ leukemias (Fig. 5A). The higher fraction of cells in cycle correlated with substantially lower transcript levels for the CDK inhibitor p16 ${ }^{\text {Ink4a }}$, whereas expression of several other cell cycle regulators including p19 ${ }^{\text {Arf }}$, an alternatively spliced Ink $4 a$ transcript that codes for a positive regulator of the p53 pathway, did not differ significantly between $M L L / v$ and $M L L / M e i s 1$ leukemias (Fig. 5B). However, expression of $B m i-1$, a negative regulator of the Ink $4 a$ locus (Jacobs et al. 1999|, was significantly higher in $M L L / M e i s 1$ leukemias (Fig. 5B). The changes in gene expression as well as latency were more pronounced in MLL-AF10 versus MLL-LAF4 leukemias. Therefore, the enabling effects of Meis1 on proliferation and arrested differentiation of $M L L$ leukemia cells correlated with specific perturbations of the $B m i-1 / \operatorname{Ink} 4 a$ axis, which is implicated in maintenance of HSC and LSC self-renewal (Lessard and Sauvageau 2003; Park et al. 2003).
A

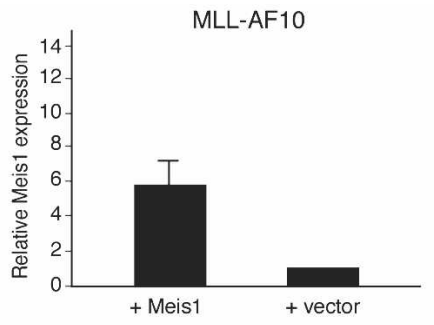

B

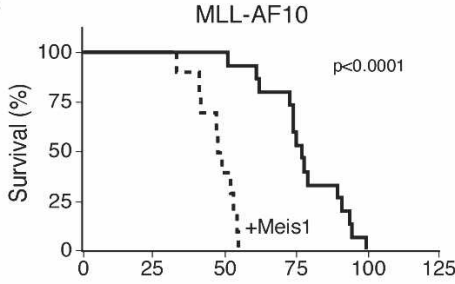

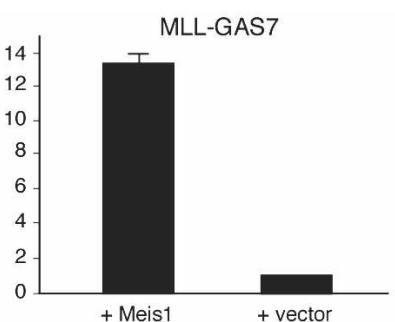
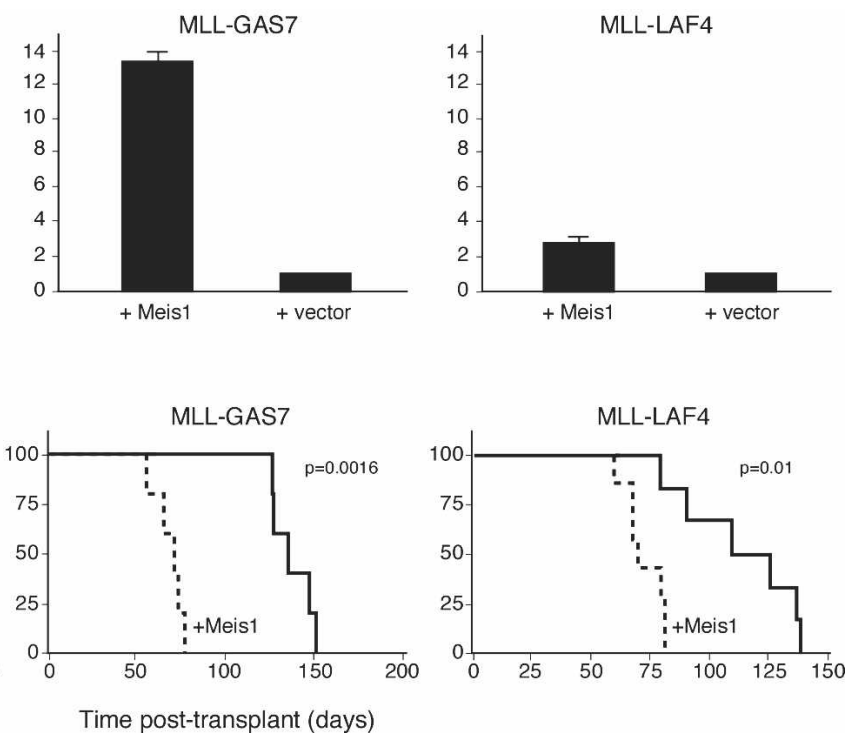

Figure 3. Increased Meis1 expression accelerates $M L L$-mediated leukemogenesis. (A) Meis1 transcript levels in myeloid progenitors (c-kit ${ }^{+}$) were determined by quantitative real-time PCR $24 \mathrm{~h}$ following transduction with retroviruses encoding the $M L L$ oncogenes indicated above the panel, with or without cotransduced Meis1 (indicated below). Data are expressed relative to the level observed in cells transduced with $M L L$ oncogene alone (bars indicate the average of triplicate analyses). (B) Survival curves are shown for cohorts of mice transplanted with cells cotransduced with the indicated $M L L$ oncogene and Meis 1 or empty vector. Acute leukemia was confirmed by peripheral blood leukocyte counts, FACS analyses, and/or necropsy. 


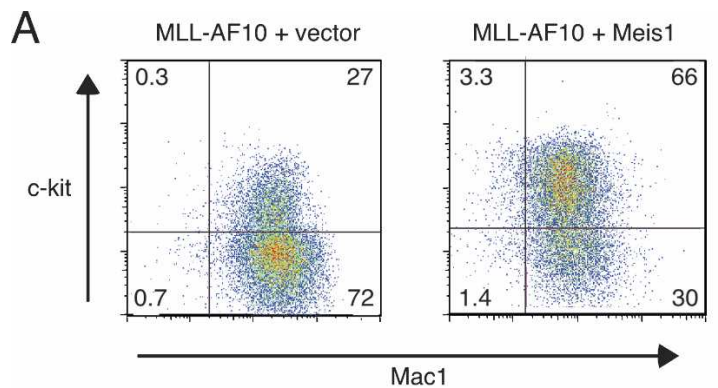

B

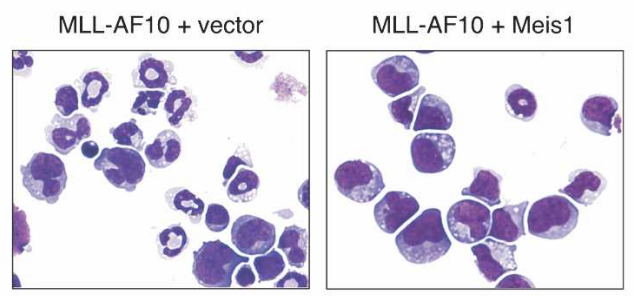

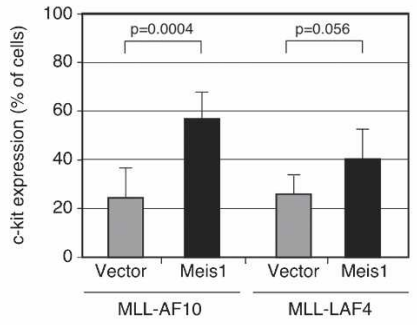

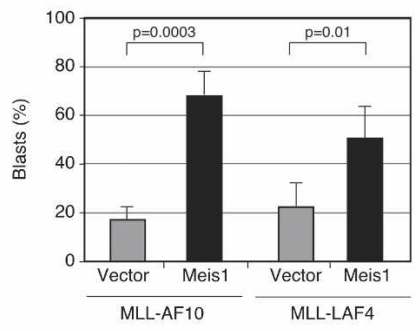

C

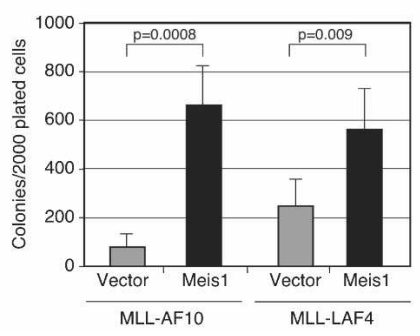

D

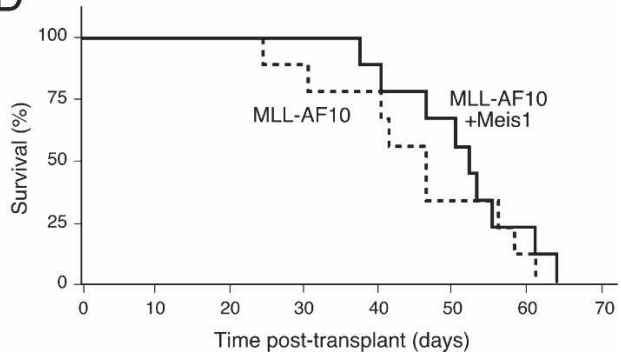

Figure 4. Meisl modulates myeloid differentiation arrest, as well as CFC and LSC frequencies of $M L L$ leukemias. (A) FACS profiles demonstrate representative c-kit and Mac1 expression on splenocytes from mice with AML induced by transplantation of progenitors transduced with genes indicated at the tops of the panels. Bar graph summarizes data from five mice in each category. $(B)$ Splenocytes from leukemic mice were analyzed for the proportion of cells with morphologic features of blasts versus differentiation following May Grunwald Giemsa staining of cytospin preparations. Bar graph indicates the number of cells with the indicated morphologic features for five mice in each cohort. (C) FACS-sorted $\mathrm{Mac1}^{+}$leukemic splenocytes were cultured in methylcellulose medium for $6 \mathrm{~d}$ to determine CFC frequencies. Bar graph indicates the numbers of clonogenic cells for each of five leukemias in the respective cohorts. (D) Survival curves of sublethally irradiated mice transplanted with single AML colonies (3000 cells) plucked after $7 \mathrm{~d}$ in semisolid culture and directly injected into secondary recipients, or expanded in semisolid culture for $5 \mathrm{~d}$ prior to injection $\left(2.5 \times 10^{5}\right.$ cells $)$.

\section{Meis1 determines MLL LSC frequency}

Previous studies of MLL-AF9 AML showed that CFCs present in the spleens of leukemic mice have the biological properties of LSCs (Somervaille and Cleary 2006). To test if the increased CFC frequencies in leukemias induced by coexpressed exogenous Meis1 also correlated with increased numbers of LSCs, individual CFCs (type I or II) were plucked from methylcellulose media and transplanted into syngeneic mice (or expanded in semisolid culture prior to transplant) to assess their potential to initiate AML in secondary recipients, a hallmark feature of LSCs. All transplanted mice succumbed to AML regardless of whether the transplanted CFCs derived from primary leukemias with or without coexpressed exogenous Meis1 (Fig. 4D). These results confirmed that CFCs in each cohort were a reliable indicator of LSCs, and demonstrated sevenfold higher LSC frequencies in $M L L / M e i s 1$ leukemias in comparison with $M L L / v$ leukemias. Unlike the case for primary transplant recipi- ents, latencies were similar irrespective of Meis1 status since the cells had achieved full leukemic potential prior to secondary transplant. Nevertheless, the morphologic features and phenotypes of the respective secondary leukemias were similar to those observed in the primary mice-i.e., a less-differentiated phenotype in leukemias coexpressing exogenous Meis1 (data not shown)-demonstrating that Meis1 expression levels stably determine LSC properties in $M L L$-associated AML.

\section{Meis1 functions as a DNA-binding transcriptional cofactor in MLL transformation}

A structure/function analysis was conducted to investigate whether Meis1 may require interactions with $\mathrm{Pbx}$ TALE protein partners for MLL-mediated transformation. Meis1 constructs containing either deletion or point mutations (in the M1/M2 domains) that abrogate Pbx interaction (G.G. Wang et al. 2005) were incapable of 

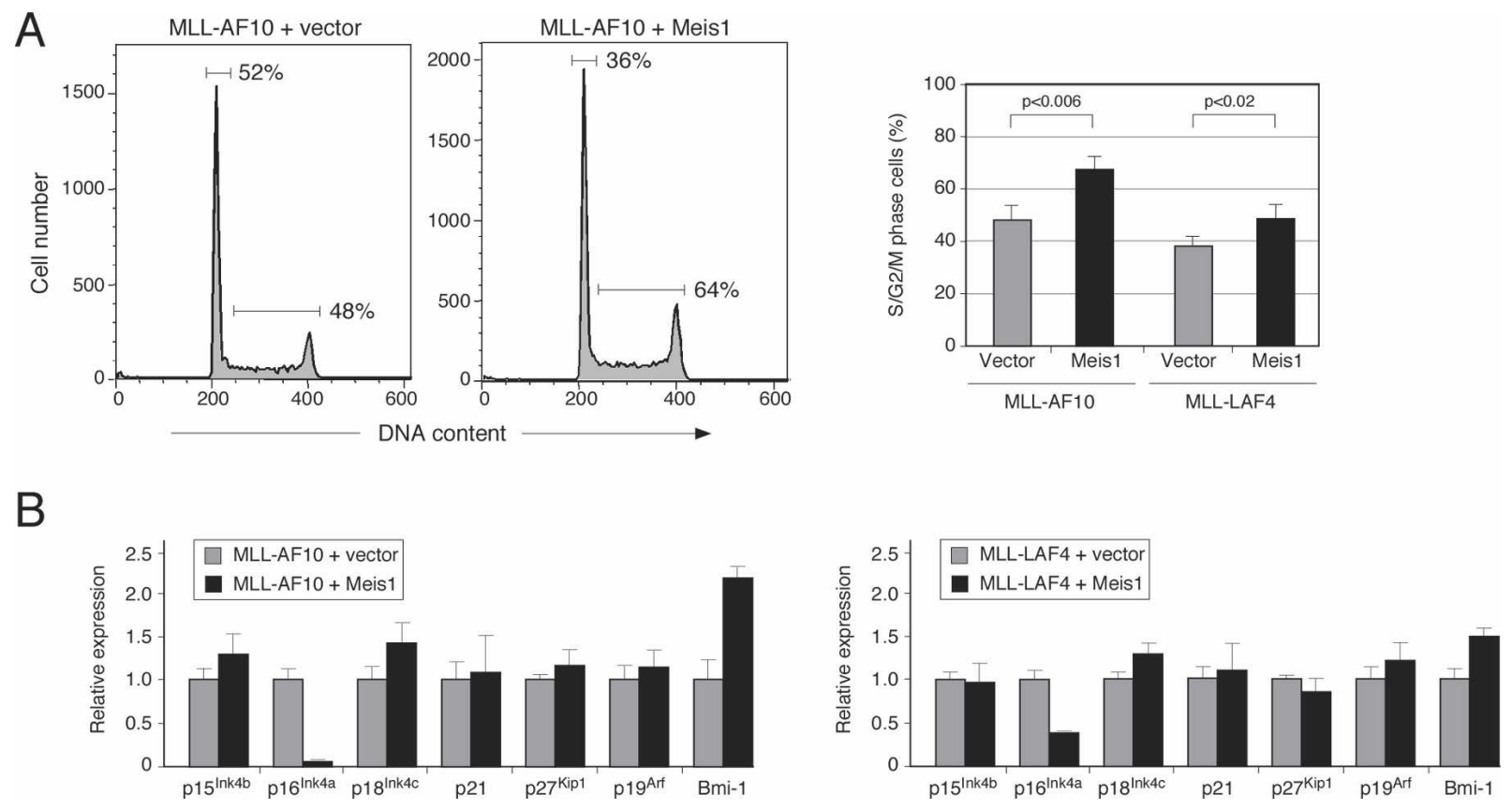

Figure 5. Altered cell cycle activity induced by Meis1 in MLL-AF10 leukemia. (A) DNA content analysis was determined by FACS analysis of explanted leukemia cells growing in methylcellulose cultures. Bar graph summarizes data for three mice in each cohort. (B) Expression levels of the indicated transcripts were determined by quantitative RT-PCR analysis of splenocytes isolated from leukemic mice. Results are the mean of three leukemias in each category, and are expressed relative to transcript levels in leukemia cells transformed by MLL-AF10.

rescuing $M L L$ transformation of Meis $1^{-/-}$FL cells (Fig. $6 \mathrm{~B}$, constructs \#2 and \#5), in contrast to wild-type Meis1 (Fig. 6B, construct \#1). Meis1 constructs containing homedomain mutations, which have been shown to disrupt Meis1 DNA binding (G.G. Wang et al. 2005), were also unable to complement Meis1 deficiency (Fig. 6A,B, constructs \#3 and \#4). Furthermore, deletion of the conserved C-terminal tail of Meis1 (Fig. 6A,B, construct \#6), which has been implicated in its transcriptional effector properties, abrogated rescue of $M L L$ transformation. Taken together, these analyses suggest that Meis1 associates with $\mathrm{Pbx}$ partners in a DNA-binding transcriptional complex to mediate $M L L$ transformation.

MLL-mediated myeloid transformation is codependent on TALE homeodomain proteins $\mathrm{Pbx} 2$ and $\mathrm{Pbx} 3$

A genetic approach was employed to interrogate the contributions of $\mathrm{Pbx}$ proteins in $M L L$ leukemia. Real-time quantitative PCR analysis showed that three $P b x$ genes $(P b \times 1, P b \times 2$, and $P b \times 3)$ were expressed in myeloid progenitors immortalized by $M L L$ oncogenes (Fig. 7A; data not shown). $P b x 3$ was notable for its significantly increased levels (three- to eightfold) compared with control cells transformed by E2A-HLF, consistent with increased $P b x 3$ levels in human MLL AMLs (Ross et al. 2004). Together, $\mathrm{Pb} \times 2$ and $\mathrm{Pbx} 3$ accounted for $>90 \%$ of total $\mathrm{Pbx}$ transcripts, whereas $P b x 1$ was minimally expressed (Fig. 7B). To investigate whether specific $P b x$ functions were required for $M L L$ transformation, serial replating assays were performed using FL cells harvested from $\mathrm{Pbx}^{-/-}$ embryos (E14.5-E18) (Rhee et al. 2004) or bone marrow cells isolated from adult $\mathrm{Pbx}^{-/-}$mice (Selleri et al. 2004; Capellini et al. 2006). MLL oncoproteins transformed the $\mathrm{Pbx}$-deficient myeloid progenitors as efficiently as wildtype cells (Supplementary Fig. 4), indicating that MLLmediated transformation was not dependent on the presence of $\mathrm{Pbx} 2$ or $\mathrm{Pbx} 3$ alone.

To further reduce $\mathrm{Pbx}$ levels, $\mathrm{Pbx} \mathrm{2}^{-/-}$cells transformed by $M L L$ oncogenes were secondarily transduced with shRNAs targeting $\mathrm{Pbx} 3$, resulting in an $\sim 70 \%-80 \%$ reduction of $P b \times 3$ transcript levels (Supplementary Fig. 3). Following $P b x 3$ knockdown, the clonogenic potential of $P b \times 2^{-/-} / P b x 3^{k d} M L L$-transformed cells was substantially decreased $(>60 \%)$ when compared with $\mathrm{Pbx}^{-/-}$ transformed cells secondarily transduced with vector alone (Fig. 7C). This effect was specific to $M L L$-mediated transformation since $\mathrm{Pbx} 2^{-/-} / \mathrm{Pb} \times 3^{k d}$ cells transformed by E2A-HLF displayed no significant reduction in clonogenic potential following $\mathrm{Pbx} 3$ silencing (Fig. 7C). These results demonstrate that maintenance of $M L L$-mediated transformation is specifically dependent on Pbx activity, and further support that Meis1 functions in complex with $\mathrm{Pbx}$ proteins in myeloid progenitors transformed by $M L L$ oncogenes.

\section{Discussion}

$M L L$ leukemias are invariably associated with expression of Hox and TALE homeobox genes, but nevertheless 

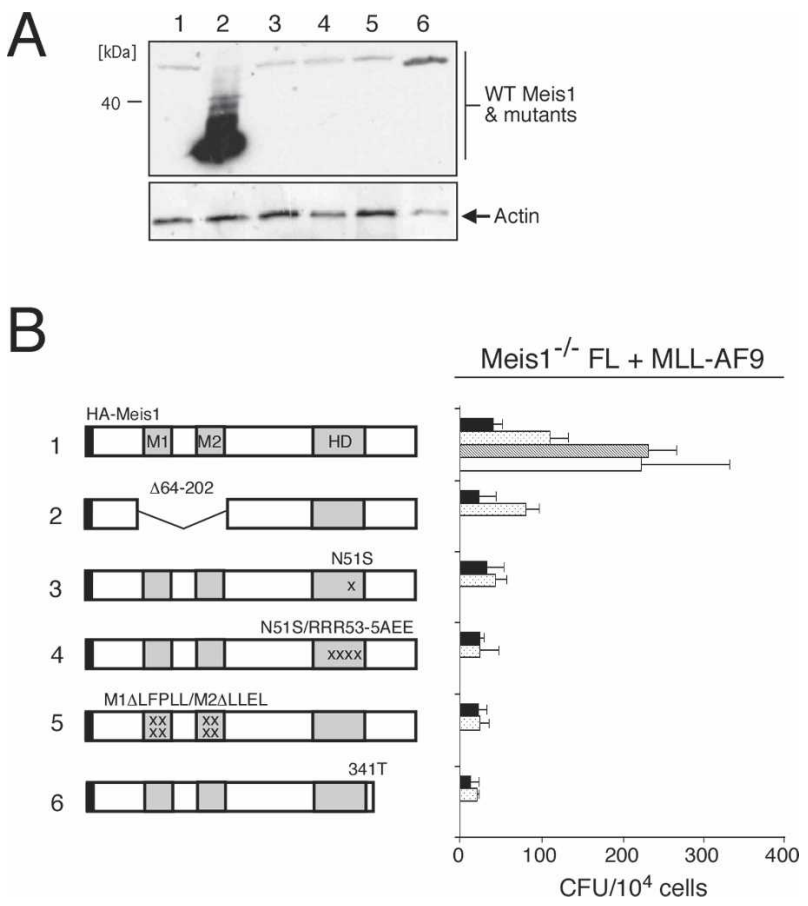

Figure 6. Structure/function analysis of Meis1 requirements in $M L L$ transformation. (A) Western blot analysis of wild-type and mutant Meis1 proteins expressed in retroviral packaging Phoenix cells and detected with an anti-HA antibody. Identities of constructs are indicated at the tops of lanes and correspond to the schematic depictions in $B$. The enhanced stability of construct \#2 lacking Pbx interaction motifs M1/M2 has been reported previously (G.G. Wang et al. 2005). (B) Myeloid transformation assay was performed using Meis $1^{-/-}$FL cells cotransduced with MLL-AF9 and various Meis1 constructs schematically illustrated on the left. Results from four rounds of plating are shown with each bar representing the mean \pm SD of the total number of myeloid colonies per $10^{4}$ plated cells derived from at least three replicates.

are clinically heterogeneous possibly reflecting differences in LSC biology and/or frequency. Misregulation of Hox genes in $M L L$ leukemias is likely to be critical for LSC maintenance, as suggested by genetic loss-of-function studies (Ayton and Cleary 2003; Kumar et al. 2004; So et al. 2004; Okada et al. 2005; J. Wang et al. 2005) and consistent with their normal roles in HSC self-renewal (Abramovich and Humphries 2005). However, Hox gene misregulation alone does not recapitulate the phenotype and biology of $M L L$ leukemias and is unlikely to support the high LSC frequencies recently demonstrated in a murine model of MLL-AF9 AML that are far in excess of those previously estimated for AML in general (Somervaille and Cleary 2006). Our current studies demonstrate that TALE homeodomain proteins are essential regulators of $M L L$ transformation, and that Meis1 in particular determines LSC frequency and potential by quantitatively regulating the extent of self-renewal, differentiation arrest, and cycling, as well as the rate of in vivo LSC generation from myeloid progenitors.
Meis1 is an essential regulator of LSC biology in MLL leukemia

Genetic analyses revealed a critical dependence on Meis1 for induction and maintenance of myeloid transformation induced by several molecularly and functionally distinct $M L L$ oncogenes. Notably, lack of Meis1 confers a consistent and severe impairment of $M L L$-mediated transformation in contrast to deficiencies of single Hoxa genes, whose requirements vary for different $M L L$ oncogenes (Ayton and Cleary 2003; Kumar et al. 2004; So et al. 2004; Okada et al. 2005; J. Wang et al. 2005; our unpublished observations). Meis1 is the predominant Meis family gene expressed in murine myeloid progenitors, and its TALE protein product functions as a transcriptional cofactor for multiple Hox proteins, which are redundantly expressed. Thus, Meis1 deficiency likely results in a broad compromise of Hox transcriptional activity, in addition to possible impacts on non-Hox-dependent pathways, and consequently a more severe limitation on $M L L$ transformation than the loss of single Hox genes.

Although Meis1 is consistently expressed and required in murine myeloid cells transformed in vitro by different MLL oncoproteins, its endogenous expression levels varied by $>20$-fold and correlated with critical features of leukemia biology and LSC frequency. Meis1 dictates the extent of myeloid differentiation arrest induced by $M L L$ oncogenes as well as the fraction of leukemia cells in cycle, and their clonogenic frequency. The similarity of these effects to those observed for Meis 1 in Hoxa9-associated leukemogenesis (Kroon et al. 1998; G.G. Wang et al. 2005) provides strong support for previous suggestions that Meis1 and Hoxa9 are major effectors of MLL leukemogenesis (Zeisig et al. 2004). Clonogenic frequency is a surrogate measure of $M L L$ LSCs (Somervaille and Cleary 2006), which are substantially increased (up to sevenfold) in AMLs associated with hyperexpression of exogenous Meis1. This correlates with observations that Meis1 programs expression of HSC-associated genes in Hoxa9-induced leukemia (G.G. Wang et al. 2005). Our studies substantially extend these observations by demonstrating that Meis1 quantitatively regulates functional properties of LSCs in a model of MLL leukemia.

\section{Meis1 is rate-limiting for MLL leukemogenesis}

Meis1 appears to serve two distinct but possibly interrelated roles in $M L L$ leukemogenesis. In addition to its requirement to initiate in vitro immortalization, the significant correlation of Meis1 expression levels with latencies required for development of $M L L$ leukemias in our mouse model supports a role for Meis1 in regulating progression of $M L L$-immortalized cells to LSCs. The genetic and/or epigenetic changes underlying this transition have not yet been defined, although it is characterized in part by acquisition of an enhanced ability to interact with the bone marrow microenvironment (Shah et al. 1998; Somervaille and Cleary 2006). A role in LSC progression is consistent with previous observations that 
Wong et al.

A

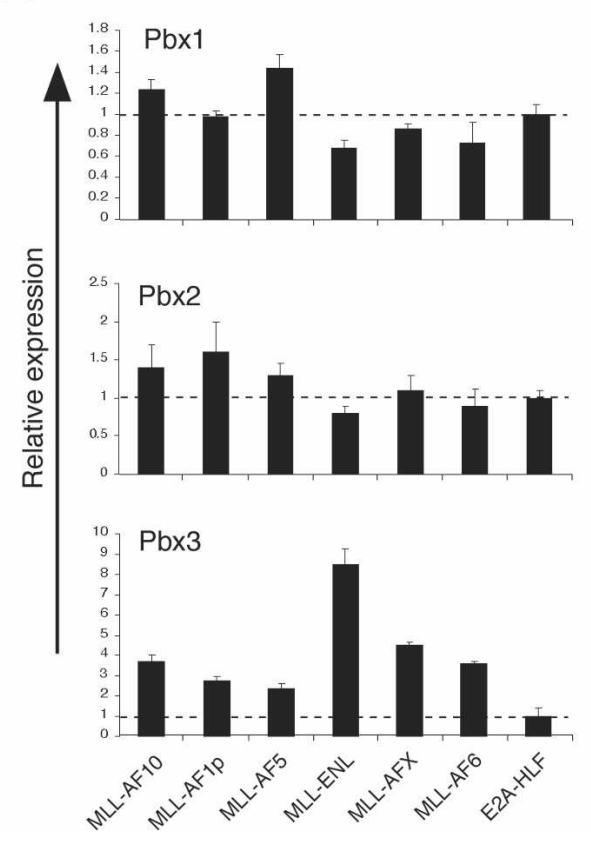

B

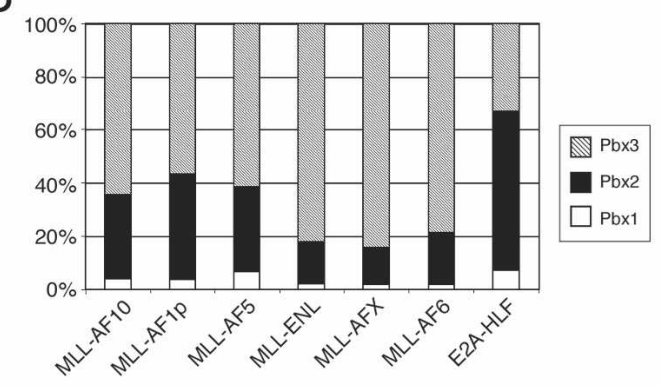

C

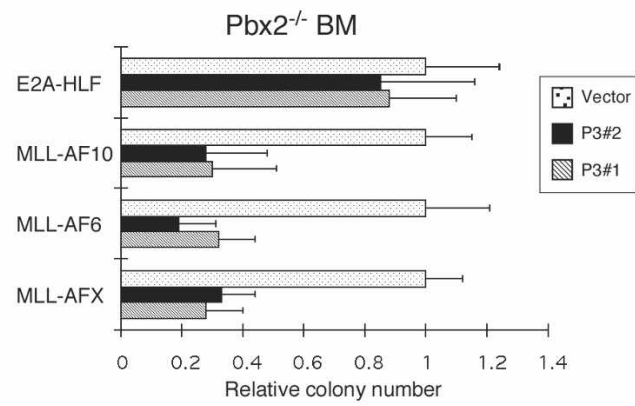

Figure 7. $P b x 2$ and $P b x 3$ are required for maintenance of $M L L$-mediated transformation. $(A)$ The relative expression levels of $P b x 1$, $P b x 2$, and $P b x 3$ transcripts were determined by real-time PCR analysis of $M L L$-transformed cells (indicated below) from the fourth round of serial replating (error bars indicate standard deviations of triplicate analyses). Results are expressed relative to levels observed in cells transformed by E2A-HLF. (B) Bar graph indicates the total relative levels of $P b x$ transcripts expressed in cells transformed by various oncogenes (indicated at bottom) from the fourth round of plating in methylcellulose cultures. The relative abundance of $P b x$ transcripts was determined using the Ct value method, assuming that all primers were optimized to generate equal PCR efficiencies. (C) $\mathrm{Pbx}^{-/-}$myeloid progenitors transformed by various oncogenes (indicated on left) were secondarily transduced with lentiviral vectors encoding shRNAs specific for $\mathrm{Pbx3}$ (P3 \#1 or P3 \#2). Colony numbers are shown relative to cells secondarily transduced with lentiviral vector alone. Error bars indicate standard deviations of at least two independent experiments.

hyperexpression of Meis1 markedly increased the penetrance and reduced the latency for development of Hoxa9-induced AML (Kroon et al. 1998; G.G. Wang et al. 2005). Thus, Meis1 is rate-limiting such that low levels temper or abrogate immortalization of myeloid progenitors in vitro, whereas high levels accelerate their in vivo transition to LSCs.

The critical influence of Meis1 on LSC biology appears to correlate with epigenetic regulation of the RB pathway. Leukemias that developed with shortened latencies following hyperexpression of exogenous Meis1 were associated with increased expression of the Bmi-1 gene, which encodes a polycomb group epigenetic repressor protein. This is consistent with previous observations that BMI-1 levels increased during step-wise transformation and immortalization of human AML (Warner et al. 2005). However, the level of Bmi-1 mRNA increase observed in our studies was relatively modest, presumably because Bmi-1 genetically opposes MLL function through its antagonistic effects on Hox gene expression (Hanson et al. 1999). Bmi-1 is essential for the maintenance of normal adult HSCs as well as LSCs (Lessard and Sauvageau 2003; Park et al. 2003), consistent with the increased LSC frequencies in $M L L / M e i s 1$ leukemias. In this capacity, Bmi-1 represses transcription of $\mathrm{p} 16^{\text {Ink } 4 \mathrm{a}}$, a CDKI at the apex of the RB pathway. Expression of p16 ${ }^{\text {Ink4a }}$ inversely correlated with Meis1 and Bmi-1 lev- els as well as the increased fraction of cycling cells in $M L L$ leukemias and the frequency of LSCs, which are highly enriched for cycling cells (T.C.P. Somervaille and M.L. Cleary, unpubl.). It was the only CDKI whose expression was consistently altered, supportive of a specific as opposed to secondary role in regulating LSC potential. Preliminary studies suggest that Bmi-1 is not a direct transcriptional target of Meis1 and is not absolutely essential for $M L L$-mediated transformation in vitro (P. Wong and M.L. Cleary, unpubl.), consistent with an alternative role in regulating long-term self-renewal that will require assessment by long-term transplantation studies. Taken together, our studies suggest that the contributions of Meis1 in generating MLL LSCs are mediated in part through the RB pathway by epigenetic modulation of Ink4a expression.

Since MLL fusion proteins, in conjunction with their essential cofactor menin, have been shown to associate with the Meis1 promoter (Milne et al. 2005; Yokoyama et al. 2005; Caslini et al. 2007), our observations raise the intriguing possibility that they may vary in their abilities to maintain expression of the Meis1 gene. Consistent with this possibility, MLL-ENL and MLL-FKBP, which differ in their oncogenic potencies, impose different histone modifications at the Meis1 promoter (Milne et al. 2005). Thus, the absolute levels of Meis1 expression may be differentially regulated by the transcrip- 
tional effector properties of individual MLL oncoproteins, which in turn dictates the rate of progression of immortalized cells to LSCs that initiate and sustain AML. This contrasts with Hox gene expression levels, which do not show a similar correlation with leukemia latencies or molecular subtypes (Supplementary Fig. 2).

Our studies suggest that TALE proteins may also critically maintain human MLL leukemia, since MEIS1 knockdown impaired the growth of leukemia cell lines. Interestingly, the relative prevalence of different $M L L$ fusion genes in human leukemias is consistent with a potential rate-limiting role for MEIS gene expression comparable with mouse leukemias. Commonly recurring $M L L$ fusion genes such as $M L L-A F 9, M L L-E N L$, $M L L-A F 6$, and $M L L-A F 10$, which were associated with the highest levels of Meis1 expression in our mouse model, comprise the vast majority of spontaneous $M L L$ associated human AMLs. Conversely, MLL-EB1 and $M L L-C B P$, which are associated with lower Meis1 expression in our model, have only rarely been observed in human AML (a single case for MLL-EB1) (Fu et al. 2005). Furthermore, $M L L-C B P$ is associated with human MDS (Satake et al. 1997) and induces an MDS-like disorder in mice (J. Wang et al. 2005), which are premalignant conditions characterized by altered self-renewal and differentiation potentials, suggesting that $M L L-C B P$ initiates transformation but does not readily facilitate progression to AML. Thus, MEIS family gene expression levels in subclinical initiated progenitors harboring $M L L$ chromosomal translocations may influence the probability of acquiring necessary secondary mutations for their conversion into LSCs capable of inducing clinical leukemia.

\section{MLL-mediated transformation is dependent on $\mathrm{Pbx}$} function

Pbx proteins heterodimerize and bind DNA with Meis proteins, which also regulate $\mathrm{Pbx}$ stability and nuclear localization. Consistent with their biochemical interactions, lack of Meis1 partially phenocopies $P b x 1$ deficiency in hematopoietic development (DiMartino et al. 2001; Hisa et al. 2004). In $M L L$ leukemias, Meis 1 contributions are dependent on the integrity of its $\mathrm{Pbx}$ dimerization motifs. Unlike the case for Meis1, however, single deficiencies of $P b x 2$ or $P b x 3$, the most highly expressed $P b x$ genes in myeloid progenitors, did not abrogate $M L L$-mediated transformation. Nevertheless, the observed reduction of clonogenic activity in $\mathrm{Pb} \times 2 / 3$ compound-deficient cells indicates that transformation of myeloid progenitors by MLL oncoproteins is dependent on $P b x$ function. This is a specific requirement and not reflective of a general suppressive effect of $P b x$ deficiency on myeloid transformation, since no impairment of proliferation or enhanced self-renewal was observed in $P b \times 2^{-1-} P b \times 3^{K D}$ cells transformed by E2A-HLF, which transforms through a Hox-independent pathway (Ayton and Cleary 2003; So et al. 2004) and would not be expected to require Hox cofactors such as $\mathrm{Pbx}$ for oncogenesis.
Dependence on the combined contributions of $\mathrm{Pbx} 2$ and $\mathrm{Pbx} 3$ may reflect their redundant properties, consistent with previous studies demonstrating that different Pbx proteins exhibit essentially identical cooperative DNA binding with a subset of Hox proteins in vitro (Chang et al. 1995). Although we cannot exclude that $\mathrm{Pbx} 2$ and $\mathrm{Pbx} 3$ make isoform-specific contributions to $M L L$ oncogenesis, it is more likely that single $P b x$ deficiencies are functionally compensated by other members of the Pbx protein family, whereas compound deficiencies reduce total $\mathrm{Pbx}$ dosage below a critical functional threshold. In support of this, novel compound-deficient $P b x$ phenotypes have recently been reported for $P b x 1$ and $P b x 2$ in limb development (Capellini et al. 2006) despite the fact that $P b x 2$ deficiency alone results in no phenotype (Selleri et al. 2004). Our data suggest that reduction of total $P b x(P b x 1, P b x 2, P b x 3)$ expression substantially below half of wild-type levels is limiting for $M L L$ transformation, thus establishing a critical role for Pbx TALE proteins.

In summary, TALE homeodomain proteins are ratelimiting for many of the biological properties that define MLL LSCs. Meis1 in particular regulates LSC frequencies and their origin from immortalized myeloid progenitors. Although deregulated Hox gene expression is consistently induced by $M L L$ fusion oncogenes, Hox protein function may be limited by the availability of TALE protein cofactors, which are more variable in their abundance and correlate with leukemia latency and biologic heterogeneity. The central role of TALE proteins in $M L L$ leukemia maintenance suggests their consideration as potential therapeutic targets, which warrants further investigation.

\section{Materials and methods}

\section{Mice}

Knockout mice deficient for $P b x 2$ (Selleri et al. 2004), $P b x 3$ (Rhee et al. 2004), and Meis1 (Hisa et al. 2004) were maintained on a C57BL/6 genetic background. C57BL/6 mice congenic for CD45 (Ly5.1/Ly5.2) were employed for transplant studies to distinguish donor and recipient cells.

\section{Cell lines}

The human leukemia cell lines MV4.11, K562, ML2, THP-1, SEMK2, and HB were obtained from the American Type Culture Collection (ATCC) or generated in our laboratory and were maintained under standard conditions.

Retroviral constructs and hematopoietic progenitor transformation assays

Retroviral constructs encoding $M L L-G A S 7, M L L-A F 1 P, M L L$ AF6, MLL-ENL, MLL-AF9, MLL-AF10, MLL-FKHRL1, MLL$A F X, M L L-C B P, E 2 A-H L F$, and Meis1 have been described previously (Lavau et al. 1997, 2000; DiMartino et al. 2002; So and Cleary 2002, 2003; So et al. 2003, 2004; Fu et al. 2005; J. Wang et al. 2005; Somervaille and Cleary 2006). Retroviral constructs encoding $M L L-L A F 4, M L L-A F 5, M L L-A F 6$, and $M L L-E B 1$ were generated by insertion of the respective cDNAs or subtotal frag- 
ments with oncogenic potential (encoding LAF4 amino acids 335-1227, AF5 amino acids 727-1163, AF6 amino acids 35-137, and EB1 amino acids 199-269;) (Imamura et al. 2002a; von Bergh et al. 2002; Fu et al. 2005) into the $M L L 5^{\prime}$ vector using standard cloning techniques. A dominant-negative Meis1 construct, analogous to known dominant-negative Drosophila and Xenopus Meis isoforms (Dibner et al. 2001; Inbal et al. 2001), was generated by deletion of C-terminal amino acids 280-390, which encode a portion of the homeodomain and downstream residues. Retroviral constructs for Meis1 $\Delta 62-202$ (Pbx1),

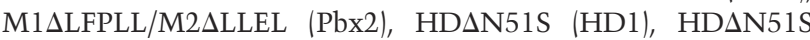
RRR53-5AEE (HD2), and Meis1 341T with a deletion of a conserved C terminus were reported previously (G.G. Wang et al. 2005). Hematopoietic transformation assays were performed essentially as described previously using primary murine myeloid progenitors harvested from bone marrow or FL (So et al. 2004). Cells transduced with retroviral vectors were selected for stable transduction in methylcellulose medium containing the appropriate antibiotic $(250 \mu \mathrm{g} / \mathrm{mL}$ hygromycin, $1 \mu \mathrm{g} / \mathrm{mL}$ puromycin, and/or $1 \mathrm{mg} / \mathrm{mL}$ neomycin).

\section{Lentivirus generation and secondary transduction}

The pSicoR lentiviral vector (Ventura et al. 2004) carrying either puromycin resistance or GFP marker genes was used for knockdown studies. shRNAs (Supplementary Table 2) were designed using pSicoOligomaker 1.5 (developed by A. Ventura, Jacks Laboratory, Cambridge, MA) and cloned into HpaI-XhoI-digested pSicoR. Lentiviral stocks were generated essentially as described previously (Ventura et al. 2004). In brief, DNA constructs encoding lentiviral vectors $(5 \mu \mathrm{g})$, CMV gag-pol-rev 8.74 $(4 \mu \mathrm{g})$, and VSVG $(1 \mu \mathrm{g})$ were cotransfected into 293T cells using FuGENE 6 reagent (Roche Diagnostics). Supernatants were collected $36-48 \mathrm{~h}$ after transfection, passed through a $0.4-\mu \mathrm{m}$ filter, and immediately incubated with immortalized cells $\left(2 \times 10^{4}\right.$ to $\left.4 \times 10^{4}\right)$ or human cell lines $\left(1 \times 10^{5}\right)$ for $12 \mathrm{~h}$ at $37^{\circ} \mathrm{C}$. Cells transduced with pSicoR-GFP vectors were cultured in liquid medium for $48 \mathrm{~h}$ and then purified by FACS sorting for GFP expression. Transduced mouse cells (2000 cells) were plated in methylcellulose medium (M3231; Stem Cell Technologies) supplemented with cytokines $(20 \mathrm{ng} / \mathrm{mL}$ SCF, $10 \mathrm{ng} / \mathrm{mL}$ IL-6, 10 $\mathrm{ng} / \mathrm{mL}$ IL-3, $10 \mathrm{ng} / \mathrm{mL}$ GM-CSF) or in MethoCult (H4236; Stem Cell Technologies) for human cells. Cells transduced with $\mathrm{pSicoR}$ carrying the puromycin resistance gene were plated $24 \mathrm{~h}$ after transduction in $0.9 \%$ methylcellulose medium (M3231) supplemented with cytokines and $1 \mu \mathrm{g} / \mathrm{mL}$ puromycin.

\section{Leukemogenicity and long-term in vivo reconstitution assays}

Transplantation experiments were performed as described previously (Lavau et al. 2000) with the following minor modifications. For cotransduction experiments, transduced progenitors were incubated in $0.9 \%$ methycellulose medium containing cytokines (20 ng/mL SCF, $10 \mathrm{ng} / \mathrm{mL}$ IL-6, $10 \mathrm{ng} / \mathrm{mL} \mathrm{IL-3)} \mathrm{in} \mathrm{the}$ presence of puromycin $(1 \mu \mathrm{g} / \mathrm{mL})$ and neomycin $(1 \mathrm{mg} / \mathrm{mL})$ for 5 $\mathrm{d}$, and then transplanted $\left(1 \times 10^{5}\right.$ cells $)$ together with a radioprotective dose of total bone marrow cells $\left(2 \times 10^{5}\right)$ into the retroorbital venous sinus of 6- to 12 -wk-old syngeneic C57BL/6 mice that had been lethally irradiated with 9.0 Gy of total body $\gamma$ irradiation $\left({ }^{135} \mathrm{Cs}\right)$. When transplanted mice exhibited signs of ill health (shortness of breath, lethargy, and hunched posture) they were euthanized. Donor and recipient cells were distinguished by FACs analysis of CD45 congenic marker expression. Necropsy tissues were fixed in buffered formalin, sectioned, and stained with hematoxylin and eosin $(H \& E)$ for histological analysis. Secondary transplants were performed by retro-orbital injection of leukemia cells $\left(3 \times 10^{3}\right.$ from a single colony or $2.5 \times 10^{5}$ expanded in semisolid medium) into sublethally irradiated (450 cGy) syngeneic C57BL/6 mice.

\section{Flow cytometry analysis}

Bone marrow and spleen cells were stained with fluorochromeconjugated monoclonal antibodies to either c-Kit (2B8 clone), Mac-1 (M1/70 clone), Gr-1 (RB6-8C5 clone), CD19 (1D3 clone), B220 (RA3-6B2 clone), CD45.1 (A20.1.7), or CD45.2 (AL1-4A2). Antibodies were purchased from PharMingen or eBioscience. Procedures employed for cell staining and FACS analysis have been described previously (So et al. 2004). DNA content analysis was performed by PI staining and analyzed by FACS.

\section{Immunoblotting}

Transiently transfected Phoenix cells were harvested and lysed in $250 \mu \mathrm{L}$ of $2 \times$ sample buffer. Proteins from $\sim 20 \mu \mathrm{L}$ of lysate were fractionated by electrophoresis through $4 \%$ sodium dodecyl sulfate-polyacrylamide gels and transferred to polyvinylidene fluoride membranes (Bio-Rad) using Tris-glycine sodium dodecyl sulfate transfer buffer. After blocking with $5 \%$ milk, membranes were incubated with monoclonal antibody N4.4 directed against an $M L L \mathrm{~N}$-terminal epitope, and then processed for chemiluminescent detection. HA-tagged Meisla proteins were detected using the M2 anti-HA monoclonal antibody (Abcam). Anti-actin (mouse monoclonal C4) was obtained from Chemicon International.

\section{Real-time quantitative PCR analysis of gene expression}

cDNA was synthesized and subjected to real-time PCR as described previously (Yokoyama et al. 2005). TaqMan probes for the following mouse and human genes were purchased from Applied Biosystems: Meis1 (Mm00487664_m1), Meis2 (Mm00487748_m1), Meis3 (Mm00485209_m1), Pbx1 (Mm00435507_m1), Pbx2 (Mm00479560_m1), Pbx3 (Mm00479413_m1), p19Arf (Mm01257348), Bmi1 (Mm00776122_gH), Cdkn1a (p21) (Mm01303209_m1), Cdkn1b (p27) (Mm00438167_g1), Cdkn2a (Mm00494449_m1), Cdkn2c (Mm00483243_m1), Cdkn4b p15 (Mm00483241_m1), ß-Actin (Mm00607939_s1); MEIS1 (Hs00180020_m1), MEIS2 (Hs00542638_m1), MEIS3 (Hs00911770_g1), and ACTB (Hs99999903_m1). Primers for mouse p16Ink4a were designed previously (Zhang et al. 2003) and purchased from Applied Biosystems. Expression levels of target transcripts relative to that of $\beta$-Actin were calculated using a standard curve and relative quantitation methods as described in ABI User Bulletin \#2. Relative dosages of Meis, $\mathrm{Pbx}$, and Hox transcripts were calculated using relative cycle time (Ct) value according to the manufacturer's instructions.

\section{Acknowledgments}

We thank P. Ayton for initially suggesting the Meis1 dependence of $M L L$ transformation. We acknowledge M. Ambrus, C. Nicolas, and K. Ochis for technical support, and A. Yokoyama, M. Lin, and J. Sage for technical guidance and assistance. We gratefully acknowledge N. Copeland (Institute of Molecular and Cell Biology, Singapore) for Meis1 knockout mice, and M. Kamps (University of California at San Diego) for Meis1 constructs. These studies were supported by the Children's Health Initiative of the Packard Foundation, grants from the National 
Institutes of Health (CA55029 and CA42971), and in part by a Croucher Foundation Research Grant to P.W. T.C.P.S. was supported by a Leukaemia Research Fund (UK) Senior Clinical Fellowship; M.I. was supported in part by the NCI-JFCR Scientist Exchange Program.

\section{References}

Abramovich, C. and Humphries, R.K. 2005. Hox regulation of normal and leukemic hematopoietic stem cells. Curr. Opin. Hematol. 12: 210-216.

Ayton, P.M. and Cleary, M.L. 2003. Transformation of myeloid progenitors by MLL oncoproteins is dependent on Hoxa7 and Hoxa9. Genes \& Dev. 17: 2298-2307.

Azpiazu, N. and Morata, G. 1998. Functional and regulatory interactions between Hox and extradenticle genes. Genes \& Dev. 12: 261-273.

Calvo, K.R., Knoepfler, P.S., Sykes, D.B., Pasillas, M.P., and Kamps, M.P. 2001. Meisla suppresses differentiation by G-CSF and promotes proliferation by SCF: Potential mechanisms of cooperativity with Hoxa9 in myeloid leukemia. Proc. Natl. Acad. Sci. 98: 13120-13125.

Capellini, T.D., Di Giacomo, G., Salsi, V., Brendolan, A., Ferretti, E., Srivastava, D., Zappavigna, V., and Selleri, L. 2006. $\mathrm{Pbx} 1 / \mathrm{Pbx} 2$ requirement for distal limb patterning is mediated by the hierarchical control of Hox gene spatial distribution and Shh expression. Development 133: 2263-2273.

Caslini, C., Yang, Z., El-Osta, M., Milne, T.A., Slany, R.K., and Hess, J.L. 2007. Interaction of MLL amino terminal sequences with menin is required for transformation. Cancer Res. 67: 7275-7283.

Chang, C.P., Shen, W.F., Rozenfeld, S., Lawrence, H.J., Largman, C., and Cleary, M.L. 1995. Pbx proteins display hexapeptide-dependent cooperative DNA binding with a subset of Hox proteins. Genes \& Dev. 9: 663-674.

Dibner, C., Elias, S., and Frank, D. 2001. XMeis3 protein activity is required for proper hindbrain patterning in Xenopus laevis embryos. Development 128: 3415-3426.

DiMartino, J.F., Selleri, L., Traver, D., Firpo, M.T., Rhee, J., Warnke, R., O'Gorman, S., Weissman, I.L., and Cleary, M.L. 2001. The Hox cofactor and proto-oncogene $\mathrm{Pbxl}$ is required for maintenance of definitive hematopoiesis in the fetal liver. Blood 98: 618-626.

DiMartino, J.F., Ayton, P.M., Chen, E.H., Naftzger, C.C., Young, B.D., and Cleary, M.L. 2002. The AF10 leucine zipper is required for leukemic transformation of myeloid progenitors by MLL-AF10. Blood 99: 3780-3785.

Eklund, E.A. 2007. The role of HOX genes in malignant myeloid disease. Curr. Opin. Hematol. 14: 85-89.

Ferrando, A.A., Armstrong, S.A., Neuberg, D.S., Sallan, S.E., Silverman, L.B., Korsmeyer, S.J., and Look, A.T. 2003. Gene expression signatures in MLL-rearranged T-lineage and Bprecursor acute leukemias: Dominance of HOX dysregulation. Blood 102: 262-268.

Fu, J.F., Hsu, H.C., and Shih, L.Y. 2005. MLL is fused to EB1 (MAPRE1), which encodes a microtubule-associated protein, in a patient with acute lymphoblastic leukemia. Genes Chromosomes Cancer 43: 206-210.

Guenther, M.G., Jenner, R.G., Chevalier, B., Nakamura, T., Croce, C.M., Canaani, E., and Young, R.A. 2005. Global and Hox-specific roles for the MLL1 methyltransferase. Proc. Natl. Acad. Sci. 102: 8603-8608.

Hanson, R.D., Hess, J.L., Yu, B.D., Ernst, P., van Lohuizen, M., Berns, A., van der Lugt, N.M., Shashikant, C.S., Ruddle, F.H., Seto, M., et al. 1999. Mammalian Trithorax and poly- comb-group homologues are antagonistic regulators of homeotic development. Proc. Natl. Acad. Sci. 96: 1437214377.

Hisa, T., Spence, S.E., Rachel, R.A., Fujita, M., Nakamura, T., Ward, J.M., Devor-Henneman, D.E., Saiki, Y., Kutsuna, H., Tessarollo, L., et al. 2004. Hematopoietic, angiogenic and eye defects in Meis 1 mutant animals. EMBO J. 23: 450-459.

Imamura, T., Morimoto, A., Ikushima, S., Kakazu, N., Hada, S., Tabata, Y., Yagi, T., Inaba, T., Hibi, S., Sugimoto, T., et al. 2002a. A novel infant acute lymphoblastic leukemia cell line with MLL-AF5q31 fusion transcript. Leukemia 16: 2302-2308.

Imamura, T., Morimoto, A., Takanashi, M., Hibi, S., Sugimoto, T., Ishii, E., and Imashuku, S. 2002b. Frequent co-expression of HoxA9 and Meis1 genes in infant acute lymphoblastic leukaemia with MLL rearrangement. Br. J. Haematol. 119: 119-121.

Inbal, A., Halachmi, N., Dibner, C., Frank, D., and Salzberg, A. 2001. Genetic evidence for the transcriptional-activating function of Homothorax during adult fly development. Development 128: 3405-3413.

Jacobs, J.J., Kieboom, K., Marino, S., DePinho, R.A., and van Lohuizen, M. 1999. The oncogene and Polycomb-group gene bmi-1 regulates cell proliferation and senescence through the ink4a locus. Nature 397: 164-168.

Krivtsov, A.V., Twomey, D., Feng, Z., Stubbs, M.C., Wang, Y., Faber, J., Levine, J.E., Wang, J., Hahn, W.C., Gilliland, D.G., et al. 2006. Transformation from committed progenitor to leukaemia stem cell initiated by MLL-AF9. Nature 442: 818 822 .

Kroon, E., Krosl, J., Thorsteinsdottir, U., Baban, S., Buchberg, A.M., and Sauvageau, G. 1998. Hoxa9 transforms primary bone marrow cells through specific collaboration with Meis1a but not Pbx1b. EMBO J. 17: 3714-3725.

Kumar, A.R., Hudson, W.A., Chen, W., Nishiuchi, R., Yao, Q., and Kersey, J.H. 2004. Hoxa9 influences the phenotype but not the incidence of Mll-AF9 fusion gene leukemia. Blood 103: $1823-1828$.

Lavau, C., Szilvassy, S.J., Slany, R., and Cleary, M.L. 1997. Immortalization and leukemic transformation of a myelomonocytic precursor by retrovirally transduced HRX-ENL. EMBO T. 16: 4226-4237.

Lavau, C., Du, C., Thirman, M., and Zeleznik-Le, N. 2000. Chromatin-related properties of CBP fused to MLL generate a myelodysplastic-like syndrome that evolves into myeloid leukemia. EMBO J. 19: 4655-4664.

Lawrence, H.J., Rozenfeld, S., Cruz, C., Matsukuma, K., Kwong, A., Komuves, L., Buchberg, A.M., and Largman, C. 1999. Frequent co-expression of the HOXA9 and MEIS1 homeobox genes in human myeloid leukemias. Leukemia 13: 19931999.

Lessard, J. and Sauvageau, G. 2003. Bmi-1 determines the proliferative capacity of normal and leukaemic stem cells. $\mathrm{Na}$ ture 423: 255-260.

Manley, N.R., Selleri, L., Brendolan, A., Gordon, J., and Cleary, M.L. 2004. Abnormalities of caudal pharyngeal pouch development in Pbx1 knockout mice mimic loss of Hox3 paralogs. Dev. Biol. 276: 301-312.

Mann, R.S. 1995. The specificity of homeotic gene function. Bioessays 17: 855-863.

Milne, T.A., Martin, M.E., Brock, H.W., Slany, R.K., and Hess, J.L. 2005. Leukemogenic MLL fusion proteins bind across a broad region of the Hox a9 locus, promoting transcription and multiple histone modifications. Cancer Res. 65: 1136711374.

Okada, Y., Feng, Q., Lin, Y., Jiang, Q., Li, Y., Coffield, V.M., Su, 
L., Xu, G., and Zhang, Y. 2005. hDOT1L links histone methylation to leukemogenesis. Cell 121: 167-178.

Park, I.K., Qian, D., Kiel, M., Becker, M.W., Pihalja, M., Weissman, I.L., Morrison, S.J., and Clarke, M.F. 2003. Bmi-1 is required for maintenance of adult self-renewing haematopoietic stem cells. Nature 423: 302-305.

Passegue, E. and Weisman, I.L. 2005. Leukemic stem cells: Where do they come from? Stem Cell Rev. 1: 181-188.

Pineault, N., Helgason, C.D., Lawrence, H.J., and Humphries, R.K. 2002. Differential expression of Hox, Meis1, and Pbxl genes in primitive cells throughout murine hematopoietic ontogeny. Exp. Hematol. 30: 49-57.

Quentmeier, H., Dirks, W.G., Macleod, R.A., Reinhardt, J., Zaborski, M., and Drexler, H.G. 2004. Expression of HOX genes in acute leukemia cell lines with and without MLL translocations. Leuk. Lymphoma 45: 567-574.

Rhee, J.W., Arata, A., Selleri, L., Jacobs, Y., Arata, S., Onimaru, H., and Cleary, M.L. 2004. Pbx3 deficiency results in central hypoventilation. Am. J. Pathol. 165: 1343-1350.

Rice, K.L. and Licht, J.D. 2007. HOX deregulation in acute myeloid leukemia. J. Clin. Invest. 117: 865-868.

Ross, M.E., Mahfouz, R., Onciu, M., Liu, H.C., Zhou, X., Song, G., Shurtleff, S.A., Pounds, S., Cheng, C., Ma, J., et al. 2004. Gene expression profiling of pediatric acute myelogenous leukemia. Blood 104: 3679-3687.

Ryoo, H.D., Marty, T., Casares, F., Affolter, M., and Mann, R.S. 1999. Regulation of Hox target genes by a DNA bound Homothorax/Hox/Extradenticle complex. Development 126: 5137-5148.

Satake, N., Ishida, Y., Otoh, Y., Hinohara, S., Kobayashi, H., Sakashita, A., Maseki, N., and Kaneko, Y. 1997. Novel MLLCBP fusion transcript in therapy-related chronic myelomonocytic leukemia with a $t(11 ; 16)(q 23 ; p 13)$ chromosome translocation. Genes Chromosomes Cancer 20: 60-63.

Schnabel, C.A., Jacobs, Y., and Cleary, M.L. 2000. HoxA9-mediated immortalization of myeloid progenitors requires functional interactions with TALE cofactors $\mathrm{Pbx}$ and Meis. Oncogene 19: 608-616.

Selleri, L., Depew, M.J., Jacobs, Y., Chanda, S.K., Tsang, K.Y., Cheah, K.S., Rubenstein, J.L., O'Gorman, S., and Cleary, M.L. 2001. Requirement for Pbx1 in skeletal patterning and programming chondrocyte proliferation and differentiation. Development 128: 3543-3557.

Selleri, L., DiMartino, J., van Deursen, J., Brendolan, A., Sanyal, M., Boon, E., Capellini, T., Smith, K.S., Rhee, J., Popperl, H., et al. 2004. The TALE homeodomain protein $\mathrm{Pbx} 2$ is not essential for development and long-term survival. Mol. Cell. Biol. 24: 5324-5331.

Shah, N., Oseth, L., and LeBien, T.W. 1998. Development of a model for evaluating the interaction between human pre-B acute lymphoblastic leukemic cells and the bone marrow stromal cell microenvironment. Blood 92: 3817-3828.

So, C.W. and Cleary, M.L. 2002. MLL-AFX requires the transcriptional effector domains of AFX to transform myeloid progenitors and transdominantly interfere with forkhead protein function. Mol. Cell. Biol. 22: 6542-6552.

So, C.W. and Cleary, M.L. 2003. Common mechanism for oncogenic activation of MLL by forkhead family proteins. Blood 101: 633-639.

So, C.W., Lin, M., Ayton, P.M., Chen, E.H., and Cleary, M.L. 2003. Dimerization contributes to oncogenic activation of MLL chimeras in acute leukemias. Cancer Cell 4: 99-110.

So, C.W., Karsunky, H., Wong, P., Weissman, I.L., and Cleary, M.L. 2004. Leukemic transformation of hematopoietic progenitors by MLL-GAS7 in the absence of Hoxa7 or Hoxa9. Blood 103: 3192-3199.
Somervaille, T.C. and Cleary, M.L. 2006. Identification and characterization of leukemia stem cells in murine MLL-AF9 acute myeloid leukemia. Cancer Cell 10: 257-268.

Swansbury, G.J. 1998. The proportion of clonal divisions varies in different hematologic malignancies. Cancer Genet. Cytogenet. 104: 139-145.

Ventura, A., Meissner, A., Dillon, C.P., McManus, M., Sharp, P.A., Van Parijs, L., Jaenisch, R., and Jacks, T. 2004. Cre-loxregulated conditional RNA interference from transgenes. Proc. Natl. Acad. Sci. 101: 10380-10385.

von Bergh, A.R., Beverloo, H.B., Rombout, P., van Wering, E.R., van Weel, M.H., Beverstock, G.C., Kluin, P.M., Slater, R.M., and Schuuring, E. 2002. LAF4, an AF4-related gene, is fused to MLL in infant acute lymphoblastic leukemia. Genes Chromosomes Cancer 35: 92-96.

Wang, G.G., Pasillas, M.P., and Kamps, M.P. 2005. Meis1 programs transcription of FLT3 and cancer stem cell character, using a mechanism that requires interaction with $\mathrm{Pbx}$ and a novel function of the Meis1 C-terminus. Blood 106: 254264

Wang, J., Iwasaki, H., Krivtsov, A., Febbo, P.G., Thorner, A.R., Ernst, P., Anastasiadou, E., Kutok, J.L., Kogan, S.C., Zinkel, S.S., et al. 2005. Conditional MLL-CBP targets GMP and models therapy-related myeloproliferative disease. EMBO J. 24: $368-381$

Warner, J.K., Wang, J.C., Takenaka, K., Doulatov, S., McKenzie, J.L., Harrington, L., and Dick, J.E. 2005. Direct evidence for cooperating genetic events in the leukemic transformation of normal human hematopoietic cells. Leukemia 19: 17941805.

Yokoyama, A., Somervaille, T.C., Smith, K.S., RozenblattRosen, O., Meyerson, M., and Cleary, M.L. 2005. The menin tumor suppressor protein is an essential oncogenic cofactor for MLL-associated leukemogenesis. Cell 123: 207-218.

Yu, B.D., Hess, J.L., Horning, S.E., Brown, G.A., and Korsmeyer, S.J. 1995. Altered Hox expression and segmental identity in Mll-mutant mice. Nature 378: 505-508.

Zeisig, B.B., Milne, T., Garcia-Cuellar, M.P., Schreiner, S., Martin, M.E., Fuchs, U., Borkhardt, A., Chanda, S.K., Walker, J., Soden, R., et al. 2004. Hoxa9 and Meis1 are key targets for MLL-ENL-mediated cellular immortalization. Mol. Cell. Biol. 24: 617-628.

Zhang, S., Qian, X., Redman, C., Bliskovski, V., Ramsay, E.S., Lowy, D.R., and Mock, B.A. 2003. p16 INK4a gene promoter variation and differential binding of a repressor, the ras-responsive zinc-finger transcription factor, RREB. Oncogene 22: 2285-2295. 


\section{Erratum}

Genes \& Development 21: 2762-2774 (2007)

Meis1 is an essential and rate-limiting regulator of $M L L$ leukemia stem cell potential

Piu Wong, Masayuki Iwasaki, Tim C.P. Somervaille, Chi Wai Eric So, and Michael L. Cleary

Due to an editing error in the above-mentioned paper, Dr. So's first name was misspelled in the published version. The correct spelling appears above.

We apologize for this error. 


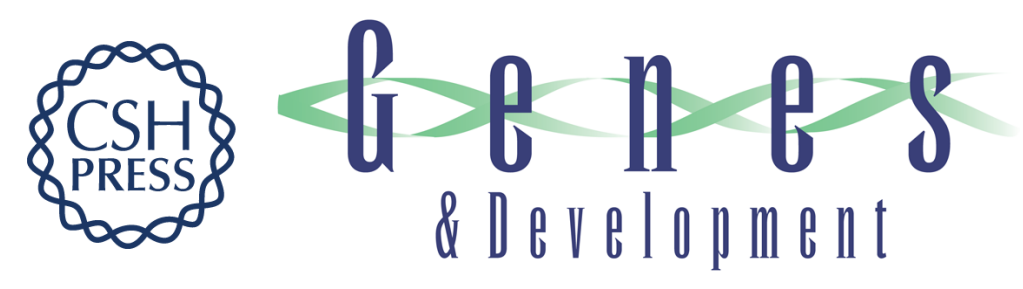

\section{Meis1 is an essential and rate-limiting regulator of $M L L$ leukemia stem cell potential}

Piu Wong, Masayuki Iwasaki, Tim C.P. Somervaille, et al.

Genes Dev. 2007, 21: originally published online October 17, 2007

Access the most recent version at doi:10.1101/gad.1602107

\section{Supplemental http://genesdev.cshlp.org/content/suppl/2007/10/17/gad.1602107.DC1 \\ Material}

Related Content

Unraveling the crucial roles of Meis1 in leukemogenesis and normal hematopoiesis Bob Argiropoulos, Eric Yung and R. Keith Humphries

Genes Dev. November, 2007 21: 2845-2849 Erratum

Genes Dev. November, 2007 21: 3017

References This article cites 59 articles, 28 of which can be accessed free at: http://genesdev.cshlp.org/content/21/21/2762.full.html\#ref-list-1

Articles cited in:

http://genesdev.cshlp.org/content/21/21/2762.full.html\#related-urls

License Freely available online through the Genes \& Development Open Access option.
Email Alerting Receive free email alerts when new articles cite this article - sign up in the box at the top Service right corner of the article or click here.

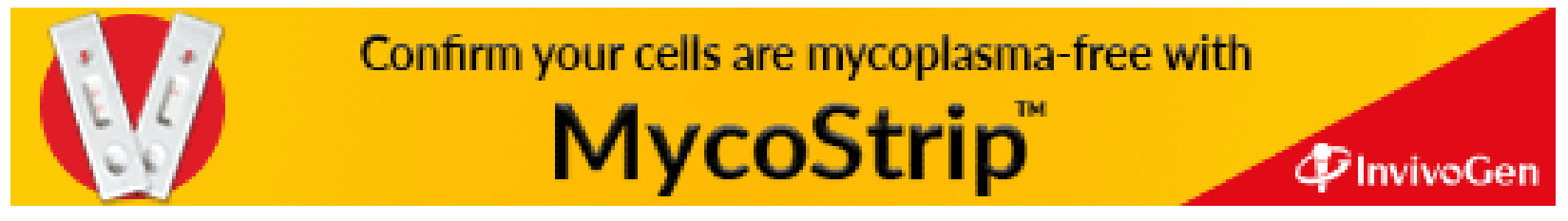

